\title{
Population Genetic Structure of Phytophthora infestans in Ecuador
}

\author{
Gregory A. Forbes, Ximena C. Escobar, Catalina C. Ayala, Jorge Revelo, \\ Maria E. Ordoñez, Barbara A. Fry, Katharine Doucett, and William E. Fry
}

\begin{abstract}
First and fifth authors: International Potato Center (CIP), P.O. Box 17-21-1977, Quito, Ecuador; second, third, and fourth authors: Instituto Nacional de Investigacion Agropecuaria (INIAP), Box 340, Quito, Ecuador; and sixth, seventh, and eighth authors: Department of Plant Pathology, 334 Plant Science, Cornell University, Ithaca, NY 14853.
\end{abstract}

Accepted for publication 19 December 1996.

\begin{abstract}
Forbes, G. A., Escobar, X. C., Ayala, C. C., Revelo, J., Ordoñez, M. E., Fry, B. A., Doucett, K., and Fry, W. E. 1997. Population genetic structure of Phytophthora infestans in Ecuador. Phytopathology 87:375-380.

The population genetic structure of Phytophthora infestans in Ecuador was assessed from 101 isolates collected from 1990 to 1992 and 111 isolates collected in 1993. All isolates were analyzed for mating type and allozyme genotype. Both samples were dominated (>95\%) by a clonal lineage (EC-1) defined from neutral markers: 90/100 genotype for glucose-6-phosphate isomerase, 96/100 genotype for peptidase, A1 mating

type, and a previously unreported nuclear DNA fingerprint. The remaining isolates belonged to the US- 1 clonal lineage, which has a worldwide distribution. Isolates in the 1993 sample were analyzed for virulence and metalaxyl sensitivity. All representatives of EC-1 had complex pathotypes, with three pathotypes representing $>60 \%$ of the collection. There was variation for metalaxyl sensitivity. There was no evidence for geographical substructuring on the basis of neutral markers, but there was evidence for limited substructuring based on metalaxyl sensitivity and specific virulence. We hypothesize that EC-1 has been recently introduced to Ecuador.
\end{abstract}

Knowledge of the population genetic structure of Phytophthora infestans (Mont.) de Bary can provide valuable insight into the overall disease epidemiology and help to explain changes in observed disease severity. Recent displacement of endemic populations of $P$. infestans by introduced genotypes has been identified as a potential source of increased losses due to greater aggressiveness of the pathogen, earlier outbreaks of disease, increased resistance to fungicides, and the capability of causing severe disease on both tomatoes and potatoes with equal aggressiveness $(5,6,17)$. Knowledge of the pathogen population structure is also useful in screening for host plant resistance and in the development of disease management strategies (11).

Both the clonal nature of this pathogen, in most parts of the world, and the existence of robust genetic markers have permitted workers to map the global migrations of $P$. infestans (5). Analysis of a limited global collection of isolates demonstrated that a single clonal lineage (US-1) is present in most countries in which potato is grown (7). This lineage is defined by a particular restriction fragment length polymorphism (RFLP) banding pattern with the probe RG57, the glucose-6-phosphate isomerase (Gpi) genotype 86/ 100 , and the peptidase (Pep) genotype 92/100 (7). All European isolates collected prior to 1980 were US-1. This, together with its worldwide distribution, has led to a hypothesis that US-1 is an old lineage that may date back to the introduction of the fungus into $\mathrm{Eu}-$ rope in the mid 1840s (7). In Mexico, the presumed center of origin of $P$. infestans, the fungus reproduces sexually, and the concept of clonal lineage has very limited utility. Sexual reproduction is now thought to occur in several parts of Europe $(3,19)$.

In this global picture, Ecuador was an interesting case. A sample collected in the 1980s of the population of P. infestans in Peru was exclusively US-1 $(7,22)$. In contrast, three isolates collected from the province of Antioquia in northern Colombia in 1990 were not US-1 (G. A. Forbes, unpublished data). The Colombian

Corresponding author: G. A. Forbes; E-mail address: forbesecip.org.ec

Publication no. P-1997-0224-02R

(C) 1997 The American Phytopathological Society isolates had the A1 mating type, but did not have either the 86 allele for Gpi or the 92 allele for Pep, which are characteristic of US-1. These observations led us to hypothesize that Ecuador may be an area in which US-1 from Peru and the other population from Colombia are converging and that genetic substructuring may exist along a north-south axis in the country. The following study was conducted to test this hypothesis and to characterize the population in Ecuador using existing markers. Because a recent review of the literature on population genetic studies of plant pathogens concluded that they are characteristically weak in sample design (11), we applied a rigorous sampling approach.

\section{MATERIALS AND METHODS}

Sampling. Two sampling strategies were used. The first was designed to provide a general overview of the population structure. For this purpose, 101 isolates were taken from the $P$. infestans collection of the International Potato Center (CIP), which is maintained in the CIP's highland research station in Quito, Ecuador. These isolates had been collected on a number of different excursions between 1990 and 1992 in the provinces of Carchi in northern Ecuador and Pichincha in northern-central Ecuador. Isolation and isolate maintenance procedures are described below.

The second sample set was collected between April and July of 1993 to test the hypothesis of population substructuring along a north-south axis in Ecuador. Samples were collected in three geographically separate production zones that primarily correspond to the provinces of Carchi in the north, Chimborazo in the central part, and Loja in the south (Fig. 1).

Since our objective was to test for population substructuring along a north-south axis, we chose to stratify our sampling to have equal probabilities of finding rare genotypes in the northern, central, and southern parts of the country. Sample sizes for each of the three production zones were determined based on the premise of finding a rare genotype which occurs at a frequency of 0.1 with a known probability of failure (e.g., $b=0.01$ or $b=0.05$ ) using the following formula:

$$
N=\log (b) / \log (1-p)
$$


in which $N=$ sample size, $b=$ the accepted probability of failure, and $p=$ the frequency of the rare genotypes (13).

Assuming rare genotypes occur randomly, sample sizes between 28 and 43 in each production zone would give us levels of probability of failure between 0.05 and 0.01 , respectively, which we considered appropriate. In Carchi and Chimborazo, 40 samples were collected; in Loja, only 31 could be found, because of dry conditions.

For the first level of stratification, we used maps at a scale of 1:200,000, each of which basically covered one production zone in the northern, central, and southern parts of the country (Fig. 1). Sample size at this stratum ranged from 31 to 40 as described above. Each map of 1:200,000 was then divided into 16 smaller land-use maps $(1: 50,000)$, which indicated the areas dedicated to major crops including potato. The 1:50,000 maps primarily delimited one political unit known as a canton and will be referred to hereafter as canton maps. The number of canton maps that contained potatogrowing areas in each production zone was four for Carchi, six for Chimborazo, and one for Loja, where potato production is of minor importance (Table 1). The 31 to 40 samples from each production zone were assigned to the individual canton maps based on their relative levels of production (Table 1). Sample sizes for canton maps ranged from 1 to 31 .

Canton maps were divided into 486 quadrats, each representing $4 \mathrm{~km}^{2}$. Quadrats were then chosen at random until a sufficient number of them (about 50) were identified that overlaid potato production as indicated on the land-use maps. For the purpose of analysis, the experimental unit consisted of one isolate from each quadrat. The sampling scheme is represented graphically (Fig. 1).
When collections were made in the field, quadrat areas were visited in their randomized order until the sufficient number of samples were collected for each canton (Table 1). One potato field was picked at random within each quadrat to be sampled. Five to 10 leaflets with single lesions were collected from each field along a transect. These were maintained at approximately $5^{\circ} \mathrm{C}$ for 1 to 2 days until isolation. In the laboratory, isolation attempts were made on five of the lesions, but only one randomly chosen isolate was used in all the analyses. Single-lesion isolates have been appropriate for allozyme and DNA analyses and appear to generally be single genotypes (8).

Isolation and maintenance of the pathogen. Isolates of $P$. infestans were trapped by placing $1-\mathrm{cm}^{2}$ pieces of infected tissue under potato slices in petri dishes. This step aids in separating $P$. infestans from saprophytes even when the infected tissue is old. Pure cultures were made by picking off small pieces of mycelium that were generally growing abundantly on the upper side of the potato slice after 7 days of incubation at $15^{\circ} \mathrm{C}$. Mycelial pieces were plated on rye $\mathrm{B}$ agar (2). After 1 to 2 weeks, growing colonies were transferred to rye A agar (2) and maintained at 5 or $15^{\circ} \mathrm{C}$ until used.

Mating type. Mating type was assessed by placing agar plugs of four isolates at equal distance around an agar plug of the known A1 isolate on $10 \%$ clarified V8 agar (9). After 14 days of incubation at $18^{\circ} \mathrm{C}$, petri dishes were assessed regularly during 4 weeks for the formation of oospores.

Virulence. Virulence was determined only for the 1993 sample. A differential set of potato cultivars representing the 11 known major genes ( $R$ genes) for resistance $(14,15)$ was provided by $L$. Turkensteen (Research Institute for Plant Protection [IPO-DLO], Wageningen, the Netherlands). Inoculum for virulence tests was

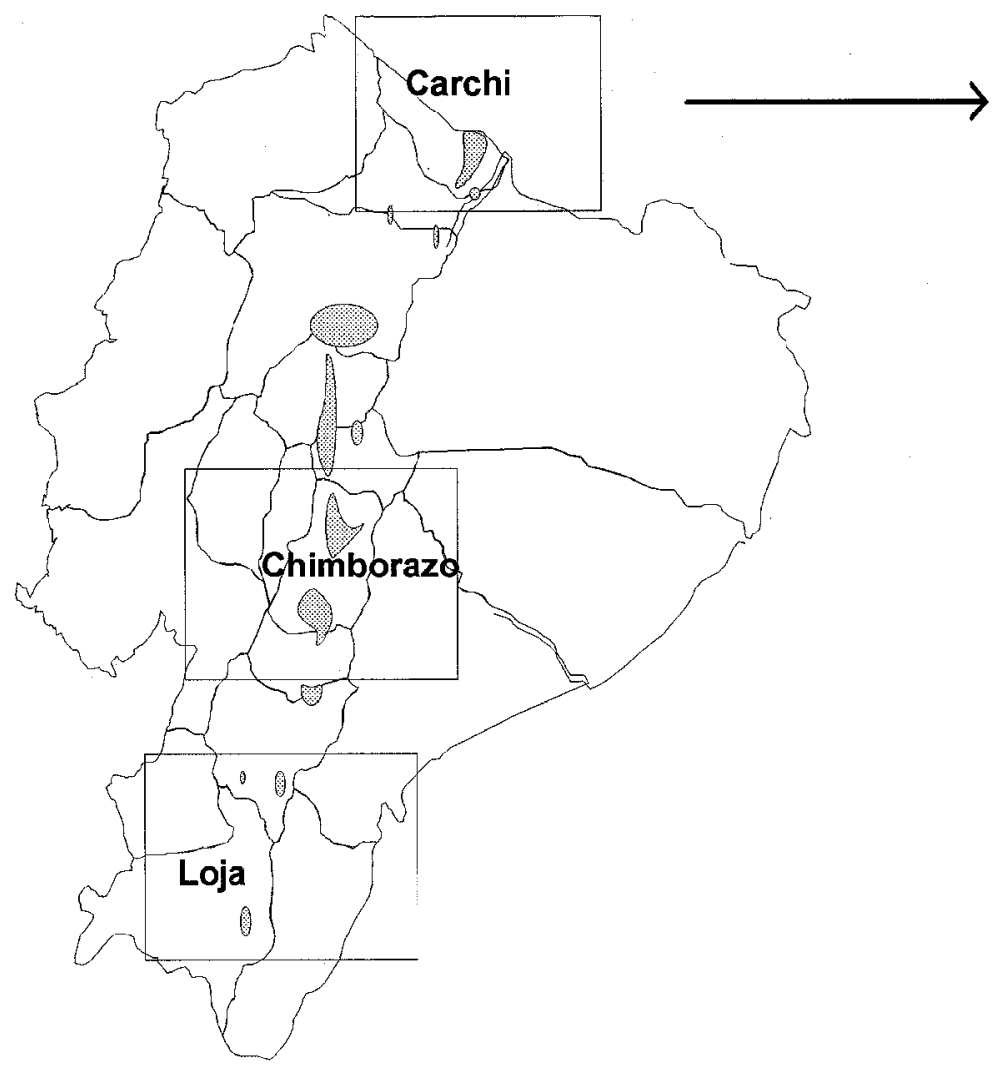

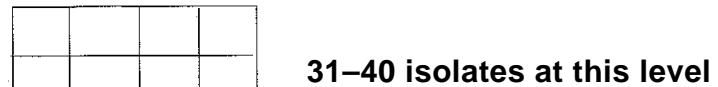

Scale $=1: 200,000$

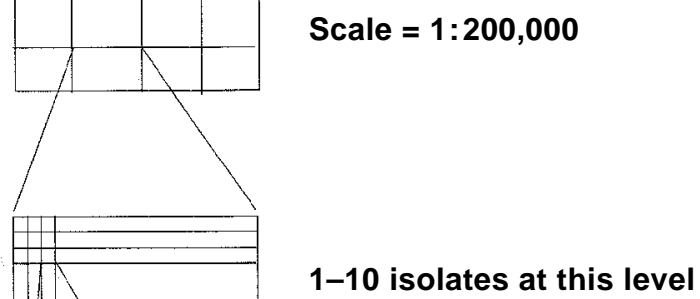

Scale $=1: 50,000$

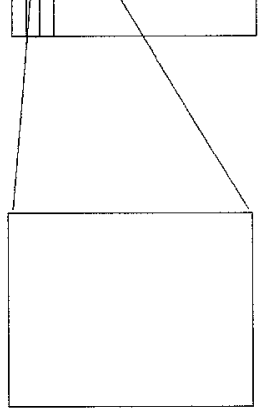

1 isolate at this level

$2 \mathrm{~km} \times 2 \mathrm{~km}$

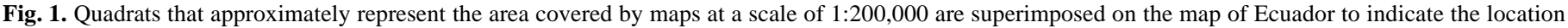

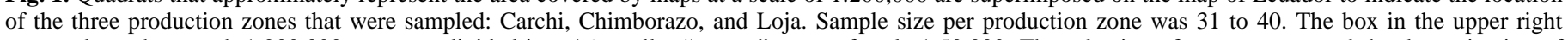

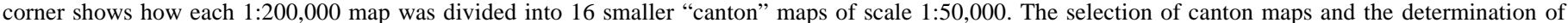

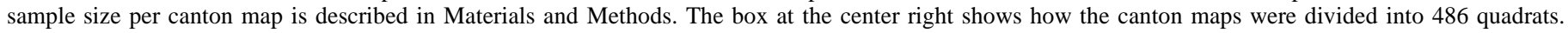

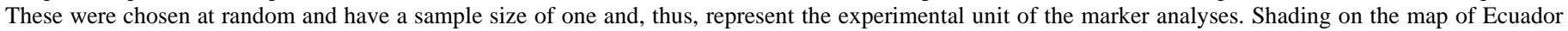
indicates areas of intense potato production. 
grown on potato tuber slices for 6 to 7 days at $15^{\circ} \mathrm{C}$ in sealed plastic trays. After incubation, tuber slices were washed gently with water to liberate sporangia. These were rinsed several times with sterile water over a $12-\mu \mathrm{m}$ mesh filter. The sporangial suspension was placed in a refrigerator for approximately $2 \mathrm{~h}$ to induce zoospore formation. Zoospores were separated from sporangia by filtration through a $12-\mu \mathrm{m}$ mesh and diluted to a concentration of $2 \times$ $10^{3} / \mathrm{ml}$. Leaflets were selected from plants that were 6 to 10 weeks old and had not yet begun to flower. The differentials were grown in a screen house in the CIP installations near Quito, Ecuador, at 3,050 $\mathrm{m}$ above sea level. Favorable growing conditions and day length (about $12 \mathrm{~h}$ ) are constant year round in Quito. Day length was extended to $16 \mathrm{~h}$ with halogen lights for the differentials, some of which do not grow well under short days. Two 10- $\mu$ l drops of inoculum were placed on the adaxial side of each leaflet to be tested. These were incubated with $12 \mathrm{~h}$ of fluorescent light (about 3,000 lux) in inverted petri dishes containing $1.5 \%$ water agar in the base.

Approximately 10 isolates were tested for virulence at one time, but all virulence assays were done with two control isolates. One control was avirulent on all of the known $11 \mathrm{R}$ genes. The second was one of two isolates, both of which are virulent on other differential cultivars including R2, R4, R10, and R11. These are the $\mathrm{R}$ genes that we consider the most difficult to score $(\mathrm{G}$. A. Forbes, unpublished data).

Virulence was scored 5 to 6 days after inoculation. A specific isolate was considered virulent on a differential cultivar when a sporulating lesion of more than $1 \mathrm{~cm}$ developed within 6 days. Nonsporulating lesions of less than $1 \mathrm{~cm}$ were considered avirulent. Ambivalent interactions were repeated. If any control interactions were ambivalent, that day's assay was repeated.

Pathotype frequencies were compared among potato production zones using a chi-square statistic of association between rows and columns (pathotypes and zones). The significance of the statistic was determined in two ways. First, we examined the level of probability from a standard chi-square test (SAS PROC FREQ, release 6.11; SAS Institute, Inc., Cary, NC). However, this test may not be appropriate when frequencies are low for any combination of factors, and several pathotypes in our study were rare or did not occur in each zone. Therefore, we also compared the observed chi-square statistic with a distribution of chi-square statistics generated from 10,000 random permutations of the data set (18).

Pathotype frequencies were also compared among zones with Hill's diversity numbers, N1 and N2 (12). N1 was calculated from

TABLE 1. Location and number of isolates collected in Ecuador from 1990 to 1993

\begin{tabular}{llr}
\hline Production zone & 1:50,000 map & No. of isolates \\
\hline 1990 to 1992 & & \\
North & San Gabriel & 58 \\
Central-north & Pichincha & 43 \\
Total (1990-1992) & & 101 \\
$1993^{\text {b }}$ & & \\
North (Carchi) & Tufino & 10 \\
& Huaca & 8 \\
& San Gabriel & 12 \\
Central (Chimborazo) & Tulcon4 & 10 \\
& Guero & 17 \\
& Guano & 9 \\
& Riobamba & 3 \\
& Guanato & 2 \\
South (Loja) & Guaranda & 1 \\
Total (1993) & Sicolpa & 8 \\
& Chuquiribamba & 31 \\
& & 111 \\
\hline
\end{tabular}

${ }^{a}$ Name of canton most closely associated with each map.

$\mathrm{b}$ The number of isolates assessed from each canton was determined by relative potato production. the Shannon index, $H^{\prime}$, by the formula $\mathrm{N} 1=e^{H^{\prime}}$. The Shannon index was estimated from the data as

$$
H^{\prime}=\sum_{i=1}^{S}\left[\left(\frac{n_{i}}{n}\right)\right] \ln \left[\left(\frac{n_{i}}{n}\right)\right]
$$

in which $S=$ pathotype, $n_{i}=$ the frequency of isolates with pathotype $i$, and $n=$ the total number of isolates in the zone (12). N2 was calculated from the Simpson index, $\lambda$, by the formula N2 = $1 / \lambda$. The Simpson index was estimated from the data as

$$
\lambda=\sum_{i-1}^{S} \frac{n_{i}\left(n_{i}-1\right)}{n(n-1)}
$$

in which $S$ = pathotype, $n_{i}=$ the frequency of isolates with pathotype $i$, and $n=$ the total number of isolates in the zone (12).

Allozyme markers. Isolates were cultivated in still culture of $10 \% \mathrm{~V} 8$ broth or pea broth (9) for 7 days at $18^{\circ} \mathrm{C}$. Protein was extracted from fresh mycelium as described by Goodwin et al. (6). Buffer systems, gel concentrations, current specifications, and staining procedures for electrophoretic analyses of Gpi and Pep were as previously described (6). Allozyme alleles are reported in migration distances relative to a commonly used control that has arbitrarily been given a value of 100 . In a small number of isolates (seven in total), the 96/100 genotype for Pep was not always clearly distinguishable from 100/100. However, the DNA fingerprint of every such isolate analyzed was identical to that of isolates with 96/100, so these isolates were assigned a Pep genotype of $96 / 100$.

Metalaxyl resistance. Metalaxyl resistance was assessed only for the 1993 sample. Assays were done at $18^{\circ} \mathrm{C}$ in the dark on $10 \%$ V8 agar amended with 5 or 100 ppm of metalaxyl. Isolates were classified as susceptible, intermediately resistant, or resistant based on radial colony growth relative to metalaxyl-free controls. To establish the classification criteria, we first plotted the radial growth at $5 \mathrm{ppm}$ against that of $100 \mathrm{ppm}$ for each isolate. We then superimposed boundary lines on the graph that were based on the criteria used by Therrien et al. (21): susceptible = radial growth less than $40 \%$ of control with both concentrations; intermediate $=$ greater than $40 \%$ with 5 ppm, but less than $40 \%$, with 100 ppm; and resistant $=$ greater than $40 \%$ with both concentrations. These were then modified slightly to avoid cases falling on classification borders (Fig. 2).

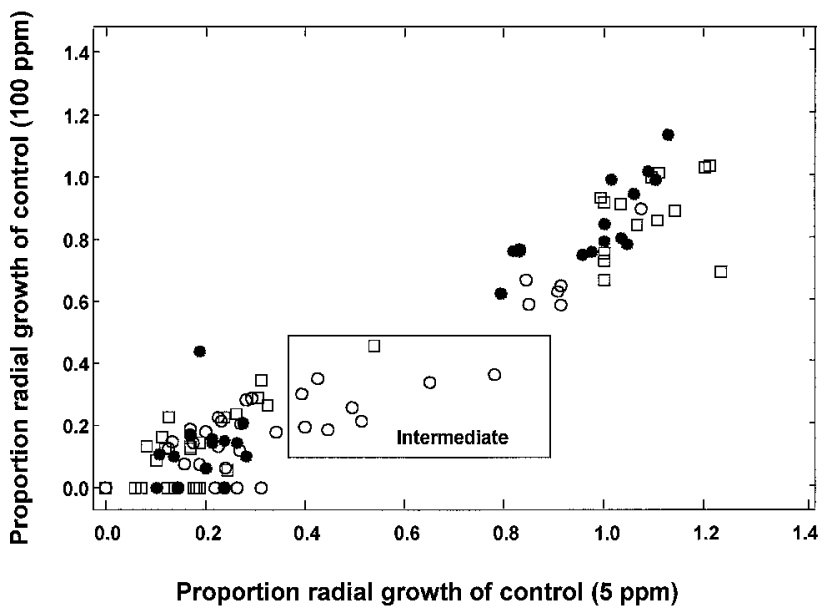

Fig. 2. Radial growth of isolates with $100 \mathrm{ppm}$ of metalaxyl plotted against radial growth with $5 \mathrm{ppm}$ of metalaxyl. Values are given as proportion radial growth of metalaxyl-free control. Samples from northern, central, and southern Ecuador are represented as boxes, open circles, and solid circles, respectively. Intermediately resistant isolates are delimited by the large box, resistant ones are to the right and above the box, and susceptible ones are to the left and below. 
DNA fingerprinting. Cultures were grown in pea broth at $18^{\circ} \mathrm{C}$ in a dark incubator. After 10 days, the fungal tissue was harvested, frozen at $-80^{\circ} \mathrm{C}$ for several hours, and then lyophilized. Lyophilized tissue was then frozen with liquid nitrogen in a mortar and ground with a pestle. DNA was extracted from the powdered mycelium as previously described (9). Gel electrophoresis, hybridization with ${ }^{32} \mathrm{P}$ random-primed probe RG57 (8), and autoradiography were all performed according to standard techniques (16).

\section{RESULTS}

1990 to 1992 sample. The early sample was characterized by predominance of one dilocus allozyme genotype representing 96 of the 101 isolates. Forty-nine isolates with the predominant al- lozyme genotype were analyzed for RFLP fingerprint, and all but one were identical, the variant differing at only one locus (Table 2 ). We have named the predominant genotype EC-1, and it is defined by the Gpi and Pep values of 90/100 and 96/100, respectively, and an RFLP banding pattern differing from US-1 by three bands (Table 2). The one isolate differing by one RFLP band is assumed to have arisen within the EC-1 lineage by mutation or mitotic recombination. Five isolates had the allozyme genotype of US-1. Three of these were analyzed for RFLP fingerprint, and all were identical to the published US-1 fingerprint (7).

1993 sample. The EC-1 dilocus allozyme genotype was even more predominant in the second sample, representing 110 of the 111 isolates tested. A subset of 17 of these was analyzed for RFLP fingerprint, and all but one were EC-1. The one variant again differed at only one locus, but a different one than that found in the

TABLE 2. Dilocus allozyme genotypes of glucose-6-phosphate isomerase (Gpi) and peptidase (Pep) alleles, and restriction fragment length polymorphism (RFLP) fingerprints of isolates of Phytophthora infestans collected in Ecuador

\begin{tabular}{|c|c|c|c|c|c|c|}
\hline \multirow[b]{2}{*}{$\underline{\text { Sample }}$} & \multicolumn{3}{|c|}{ Dilocus allozyme genotype } & \multicolumn{3}{|c|}{ RFLP fingerprint } \\
\hline & Number & Gpi & Pep & Number & Bands 1 to 25 & Lineage $^{\mathrm{a}}$ \\
\hline \multicolumn{7}{|c|}{1990 to 1992} \\
\hline & 5 & $86 / 100$ & $92 / 100$ & 3 & 1011101011001101000110011 & US-1 \\
\hline & 1 & $90 / 100$ & $96 / 100$ & 1 & $1111101001001 \underline{0} 01000111011$ & $\mathrm{EC}-1^{\mathrm{b}}$ \\
\hline \multicolumn{7}{|l|}{1993} \\
\hline & 1 & $86 / 100$ & $92 / 100$ & $\mathrm{NT}^{\mathrm{c}}$ & & US-1 \\
\hline
\end{tabular}

${ }^{a}$ Clonal lineages were determined by DNA fingerprint and allozyme genotype.

${ }^{\mathrm{b}}$ Differs from predominant EC-1 genotype by one locus (underlined).

c Not tested.

TABLE 3. Pathotypes of Phytophthora infestans collected in three production zones ${ }^{\mathrm{a}}$ in Ecuador in 1993

\begin{tabular}{|c|c|c|c|c|c|c|c|c|}
\hline \multirow[b]{2}{*}{ Pathotype $^{b}$} & \multicolumn{2}{|c|}{ Carchi } & \multicolumn{2}{|c|}{ Chimborazo } & \multicolumn{2}{|c|}{ Loja } & \multicolumn{2}{|c|}{ Total } \\
\hline & No. & $\%$ & No. & $\%$ & No. & $\%$ & No. & $\%$ \\
\hline $\mathrm{R} 1,2,3,4,7,8,10,11$ & 9 & 23.1 & 2 & 5.3 & 4 & 12.9 & 15 & 13.9 \\
\hline $\mathrm{R} 1,3,4,7,10,11$ & 3 & 7.7 & 8 & 21.1 & 10 & 32.3 & 21 & 19.4 \\
\hline $\mathrm{R} 3,4,7,8,10,11$ & 1 & 2.6 & 2 & 5.3 & 1 & 3.2 & 4 & 3.7 \\
\hline $\mathrm{R} 1,2,3,4,7,10,11$ & 3 & 7.7 & 1 & 2.6 & & & 4 & 3.7 \\
\hline R3,4,7,10,11 & 1 & 2.6 & 1 & 2.6 & & & 2 & 1.9 \\
\hline $\mathrm{R} 2,3,4,7,8,10,11$ & 4 & 10.3 & & & & & 4 & 3.7 \\
\hline $\mathrm{R} 2,4,7,10,11$ & 1 & 2.6 & & & & & 1 & 0.9 \\
\hline $\mathrm{R} 3,4,7,11$ & 1 & 2.6 & & & & & 1 & 0.9 \\
\hline $\mathrm{R} 3,7,11$ & 1 & 2.6 & & & & & 1 & 0.9 \\
\hline $\mathrm{R} 1,2,3,4,5,6,7,8,9,10,11$ & & & 1 & 2.6 & & & 1 & 0.9 \\
\hline $\mathrm{R} 1,2,3,4,7,11$ & & & 1 & 2.6 & & & 1 & 0.9 \\
\hline $\mathrm{R} 12,3,4,6,7,8,9,10,11$ & & & & & 1 & 3.2 & 1 & 0.9 \\
\hline $\mathrm{R} 1,3,4,10$ & & & & & 1 & 3.2 & 1 & 0.9 \\
\hline $\mathrm{R} 1,3,4,7,11$ & 3 & 7.7 & & & 1 & 3.3 & 1 & \\
\hline $\mathrm{r}$ (no virulence) & 1 & 2.6 & & & & & 1 & 0.9 \\
\hline Total $^{\mathrm{c}}$ & 39 & 100 & 38 & 100 & 31 & 100 & 108 & 100 \\
\hline Number of pathotypes & 14 & & 14 & & 8 & & & \\
\hline Hill's N1 ${ }^{\mathrm{d}}$ & 10.25 & & 8.38 & & 4.71 & & & \\
\hline Hill's $N 2^{e}$ & 9.88 & & 6.28 & & 3.97 & & & \\
\hline
\end{tabular}

${ }^{\mathrm{a}}$ The chi-square statistic for dependence of pathotypes and zones was 64.3 (46 degrees of freedom), which was significant at $P=0.043$ (SAS PROC FREQ, release 6.11; SAS Institute, Inc., Cary, NC), and at $P<0.001$ when compared with a distribution of chi-square statistics generated from 10,000 random permutations of the data.

${ }^{\mathrm{b}}$ Numbers represent known R genes overcome by that pathogen phenotype.

${ }^{\mathrm{c}}$ Data were inconclusive for three of the 111 isolates.

${ }^{\mathrm{d}}$ Hill's N1 is an indication of the number of abundant pathotypes. It is calculated as N1 $=e^{H^{\prime}}$, in which $H^{\prime}$ is the Shannon index of diversity (12).

e Hill's N2 is an indication of the number of "very" abundant pathotypes (12). It is calculated as N2 $=1 / \lambda$, in which $\lambda$ is the Simpson index of diversity (12). 
early sample (Table 2). Only one US-1 dilocus allozyme genotype was found in 1993. It was not analyzed for RFLP fingerprint.

Most isolates in the 1993 sample were virulent on six or more $\mathrm{R}$ genes. The specific pathotypic structure differed significantly among the three production zones based on a chi-square analysis (Table 3 ). In spite of this, the three most common pathotypes, having eight, seven, and eight virulence factors, respectively, represented $62.9 \%$ of the sample and were found in a relatively high frequency in all three production zones. Numerous other pathotypes were unique to one of the zones, but these were only found once or in low frequencies. One isolate was avirulent on all $\mathrm{R}$ genes, and this was the only US-1 isolate found in the 1993 sample.

Pathotype diversity was greatest in the northern zone (Carchi), intermediate in the central zone, and lowest in the southern zone (Table 3). Hill's diversity number N1, which is an estimate of the number of abundant pathotypes (12), was twice as large in the north $(\mathrm{N} 1=10.25)$ as in the south $(\mathrm{N} 1=4.71)$. The diversity number $\mathrm{N} 2$, which is a measure of "very" abundant pathotypes (12), indicated a pattern of generally linear decrease in diversity from north to south.

Approximately one-third (34\%) of all isolates from 1993 were highly resistant to metalaxyl (Table 4 and Fig. 2). The frequency of resistance was similar in the north (Carchi) and south (Loja) of Ecuador, but lower in the central part (Chimborazo), which was the only zone in which intermediately resistant isolates were not rare $(20 \%)$. This disparity resulted in a highly significant $(P=$ $0.002)$ chi-square test for homogeneity of metalaxyl resistance among production zones (Table 4).

All isolates from both samples were A1 mating type.

\section{DISCUSSION}

The A2 mating type has not been found among isolates of $P$. infestans taken from cultivated potato in Ecuador, so clonal populations are to be expected. Our survey provides strong evidence that this population is predominantly made up of one lineage, which we have named EC-1 in accordance with the nomenclature established by Goodwin et al. (7). Therefore, we reject the hypothesis that a frontier exists within Ecuador between the Peruvian US-1 population sampled in the 1980s $(7,22)$ and a distinct population that we had subsequently detected in Colombia. Rather, the potato production zones in all parts of Ecuador are characterized by almost complete predominance of EC-1. In the stratified sample of 1993, all but one isolate were EC-1.

Within EC-1, there was some variation for neutral markers. For example, one isolate in each sample varied from the predominant EC-1 genotype by one RFLP band (Table 2). Goodwin et al. (7) found a single locus deviation of US-1 in the Philippines, which they designated as US-1.1. The population in the Philippines is also asexual, and the single-locus change was assumed to be the result of mutation or mitotic recombination. Similarly, in our study, the variants were identical to EC-1 for mating type and dilocus allozyme genotype, so we assume they arose within the EC-1 lineage either by mutation or mitotic recombination. The frequency of the variants was low (one in 17 in the stratified sample), and we do not believe it is appropriate or necessary, at this point, to name specific genotypes within the EC-1 lineage.

Although our study did not indicate geographical substructuring in the population of $P$. infestans in Ecuador for neutral markers, there was a difference in metalaxyl resistance among the production zones and a less noticeable, but statistically significant, difference among zones for specific virulence. Differences in fungicide-use patterns may explain the regionality of the fungicide resistance data, but we have no information on fungicide usage in different parts of Ecuador. Fry et al. (4) found that levels of metalaxyl resistance were higher in populations of $P$. infestans coming from production fields in the Netherlands, where metalaxyl was frequently used, than in populations coming from home gardens were metalaxyl was seldom used.
The diversity of virulence pathotype among isolates and among regions is not immediately attributable to any specific factor(s). A statistical test indicated that pathotype structure was associated with production zones, and diversity measures indicated a strong north-south trend. It is not clear why this pattern should exist, but it could be an indication that EC-1 has migrated within Ecuador from north to south. The southern population of EC-1 could represent a subset of what is in the north. Overall, the level of diversity among pathotypes within EC-1 is similar to the diversity within clonal lineages recently reported from the United States (10) and from Poland (20).

Selection by $\mathrm{R}$ gene-containing potatoes (10) in Ecuador is probably not the reason for the presence of complex pathotypes in EC-1. Studies done recently at the CIP experiment station in Quito indicate that most Ecuadorian cultivars are either free of $\mathrm{R}$ genes or contain R genes 1 and 3 (P. J. Oyarzun and G. A. Forbes, unpublished data). Furthermore, cultivars grown in the south of Ecuador are free of known $\mathrm{R}$ genes, and isolates we collected there in 1993 were also highly virulent. Excess virulence in EC-1 was probably imported with the lineage and has remained "unused." Thus, the situation in Ecuador parallels that in the Netherlands in that the level of specific virulence increased dramatically after the detection of immigration (4). Other workers have also found high levels of virulence in populations of $P$. infestans that can not be explained by the $\mathrm{R}$ gene constitution of the potato cultivars being grown (14). These observations lend support to the argument that stabilizing selection, i.e., selection against the accumulation of unnecessary virulence (24), is not important in the P. infestanspotato pathosystem (23).

Data from this study lead us to suggest a new hypothesis concerning the genetic structure of $P$. infestans in Ecuador: EC-1 is a recently introduced clonal lineage that has displaced US-1 on potatoes. This hypothesis is consistent with the conclusion of Goodwin et al. (7) that most continents were dominated by clonal populations of US-1 until recently. Early data from Peru are consistent with that conclusion; collections from the early 1980s identified only US-1 from Peru (22). In addition to the data from analysis of neutral markers, the pathotypic data are also consistent with our new hypothesis. In studies with isolates collected from potatoes in Ecuador in the 1970s (1) and from potatoes in Peru in the 1980s (22), highly complex pathotypes were not found, and most isolates were avirulent on potatoes with $\mathrm{R}$ genes. In contrast, in our study with isolates collected in the early 1990s, we found most isolates to be highly complex. Thus, the current population of $P$. infestans in Ecuador seems very different from the population that existed in the 1970s. Also consistent with our hypothesis is our finding that isolates of EC-1 were highly complex, but that the only completely avirulent isolate detected in our study was an isolate of US-1.

\section{ACKNOWLEDGMENTS}

This research was supported, in part, by grant HRN-5600-G-00-204400 in the program in Science and Technology Cooperation, Office of the

TABLE 4. Numbers of isolates of Phytophthora infestans collected in three production zones of Ecuador that were either resistant, moderately resistant, or sensitive to metalaxyl

\begin{tabular}{lcccc}
\hline & \multicolumn{4}{c}{ Level of resistance } \\
\cline { 2 - 5 } Production zones $^{\mathrm{a}}$ & Resistant & Intermediate & Sensitive & Total \\
\hline Carchi & 15 & 1 & 24 & 40 \\
Chimborazo & 6 & 8 & 26 & 40 \\
Loja & 16 & 0 & 14 & 30 \\
Total & 37 & 9 & 64 & $110^{\mathrm{b}}$ \\
\hline
\end{tabular}

${ }^{a}$ Chi-square analysis of association between zones and resistance classes was highly significant: $\chi^{2}=17.364, P=0.002$, and degrees of freedom $=4$.

${ }^{\mathrm{b}}$ One isolate could not be assessed. 
Science Advisor, U.S. Agency for International Development. We thank K. Garrett for assistance with nonparametric statistical analyses.

\section{LITERATURE CITED}

1. Anonymous. 1976. Informe Anual de Actividades. Departamento de Fitopatologia, Instituto Nacional de Investigaciones Agropecuarias (INIAP), Quito, Ecuador.

2. Caten, C. E., and Jinks, J. L. 1968. Spontaneous variability of single isolates of Phytophthora infestans. I. Cultural variation. Can. J. Bot. 46:329-348.

3. Drenth, A., Goodwin, S. B., Fry, W. E., and Davidse, L. C. 1993. Genotypic diversity of Phytophthora infestans in the Netherlands revealed by DNA polymorphisms. Phytopathology 83:1087-1092.

4. Fry, W. E., Drenth, A., Spielman, L. J., Mantel, B. C., Davidse, L. C., and Goodwin, S. B. 1991. Population genetic structure of Phytophthora infestans in the Netherlands. Phytopathology 81:1330-1336.

5. Fry, W. E., Goodwin, S. B., Dyer, A. T., Matuszak, J. M., Drenth, A., Tooley, P. W., Sujkowski, L. S., Koh, Y. J., Cohen, B. A., Spielman, L. J., Deahl, K. L., Inglis, D. A., and Sandlan, K. P. 1993. Historical and recent migrations of Phytophthora infestans: Chronology, pathways, and implications. Plant Dis. 77:653-661.

6. Goodwin, S. B., Cohen, B. A., Deahl, K. L., and Fry, W. E. 1994. Migration from northern Mexico was the probable cause of recent genetic changes in populations of Phytophthora infestans in the United States and Canada. Phytopathology 84:553-558.

7. Goodwin, S. B., Cohen, B. A., and Fry, W. E. 1994. Panglobal distribution of a single clonal lineage of the Irish potato famine fungus. Proc. Natl. Acad. Sci. U.S.A. 91:11591-11595.

8. Goodwin, S. B., Drenth, A., and Fry, W. E. 1992. Cloning and genetic analyses of two highly polymorphic, moderately repetitive nuclear DNAs from Phytophthora infestans. Curr. Genet. 22:107-115.

9. Goodwin, S. B., Spielman, L. J., Matuszak, J. M., Bergeron, S. N., and Fry, W. E. 1992. Clonal diversity and genetic differentiation of Phytophthora infestans populations in northern and central Mexico. Phytopathology 82:955-961.

10. Goodwin, S. B., Sujkowski, L. S., and Fry, W. E. 1995. Rapid evolution of pathogenicity within clonal lineages of the potato late blight disease fungus. Phytopathology 85:669-676.
11. Leung, H., Nelson, R. J., and Leach, J. E. 1993. Population structure of plant pathogenic fungi and bacteria. Adv. Plant Pathol. 10:157-205

12. Ludwig, J. A., and Reynolds, J. F. 1988. Statistical Ecology: A Primer on Methods and Computing. John Wiley \& Sons, New York.

13. Mainland, G. B. 1951. Muller's method of calculating population sizes for synthesizing new stocks or lines. J. Hered. 42:237-240.

14. Malcolmson, J. F. 1969. Races of Phytophthora infestans occurring in Great Britain. Trans. Br. Mycol. Soc. 53:417-423.

15. Malcolmson, J. F., and Black, W. 1966. New R genes in Solanum demissum Lindl. and their complementary races of Phytophthora infestans (Mont.) de Bary. Euphytica 15:199-203.

16. Maniatis, T. A., Fritsch, J. F., and Sambrook, J. 1982. Molecular Cloning: A Laboratory Manual. Cold Spring Harbor Laboratory, Cold Springs Harbor, NY.

17. Spielman, L. J., Drenth, A., Davidse, L. C., Sujkowski, L. J., Gu, W., Tooley, P. W., and Fry, W. E. 1991. A second world-wide migration and population displacement of Phytophthora infestans. Plant Pathol. 40:422-430.

18. Sprent, P. 1993. Applied Nonparametric Statistical Methods. Chapman and Hall, London.

19. Sujkowski, L. S., Goodwin, S. B., Dyer, A. T., and Fry, W. E. 1994. Increased genotypic diversity via migration and possible occurrence of sexual reproduction of Phytophthora infestans in Poland. Phytopathology 84:201-207.

20. Sujkowski, L. S., Goodwin, S. B., and Fry, W. E. 1996. Changes in specific virulence in Polish populations of Phytophthora infestans: 19851991. Eur. J. Plant Pathol. 102:555-561.

21. Therrien, C. D., Tooley, P. W., Spielman, L. J., Fry, W. E., Ritch, D. L., and Shelly, S. E. 1993. Nuclear DNA content, allozyme phenotypes and metalaxyl sensitivity of Phytophthora infestans from Japan. Mycol. Res. 97:945-950

22. Tooley, P. W., Therrien, C. D., and Ritch, D. L. 1989. Mating type, race composition, nuclear DNA content, and isozyme analysis of Peruvian isolates of Phytophthora infestans. Phytopathology 79:478-481.

23. Turkensteen, L. J. 1993. Durable resistance of potatoes against Phytophthora infestans. Pages 115-124 in: Durability of Disease Resistance. T. Jocobs and J. E. Parlevliet, eds. Kluwer Academic Publishers, Dordrecht, the Netherlands.

24. van der Plank, J. E. 1968. Disease Resistance in Plants. Academic Press, New York. 